\title{
artigos
}

DOI: 10.11606/issn.2318-8855.v6i6p149-164

\section{A Atividade Cafeeira em Ribeirão Preto/SP (1904-1936)}

Ulysses de Paiva Faleiros Neto*

Resumo: Este artigo apresenta a análise de dados relativos à estrutura produtiva do complexo cafeeiro em Ribeirão Preto/SP. Nosso objetivo foi compreender com maior amplitude as estruturas produtivas do café no município, afim de revelar o perfil dos produtores locais. Este trabalho iniciase com um breve histórico da economia brasileira e a apresentação do nosso espaço de estudo, o município, e estabelece suas relações com a produção de café, que se fortalecem principalmente a partir de 1870. No segundo momento, apresentamos os dados obtidos através do levantamento feito no Arquivo Público e Histórico de Ribeirão Preto (APHRP) em fontes primárias - são elas a Estatística Agrícola e Zootécnica de Ribeirão Preto (1904-1905) e o Livro de Imposto do Cafeeiro (1916-1936). Através das informações contidas nestes documentos foi possível constituir séries históricas que nos possibilitaram compreender a estrutura produtiva relativa ao café no município. Os resultados obtidos permitiram a compreensão das possíveis relações entre a atividade cafeeira no município e a economia nacional e internacional.

Palavras-chave: Cafeicultura; História Econômica; Ribeirão Preto/SP.

\section{Introdução}

Pretendemos neste estudo analisar a estrutura produtiva do complexo cafeeiro em Ribeirão Preto/SP. A economia cafeeira deixou uma marca indelével na história da localidade, sendo impossível compreender nossa formação histórica sem analisar as características e o funcionamento desta atividade.

Ao trabalharmos com fontes primárias pretendemos construir séries históricas que retratem com maior fidelidade as estruturas produtivas do período abordado neste estudo. De tal modo, o

\footnotetext{
* Graduado em História pelo Centro Universitário Barão de Mauá. Discente do curso de Geografia no Centro Universitário Claretiano. Professor no Serviço Social da Indústria (SESI), atuando na disciplina de História.
} 


\section{artigos}

Ulysses de Paiva Faleiros Neto

que pretendemos analisar é a constituição das propriedades no município, ou seja, se eram pequenas, médias ou grandes propriedades que predominavam na localidade e como os donos dessas propriedades se comportaram economicamente em relação aos seus cafezais durante o período.

Os referenciais teóricos/metodológicos oferecidos pela história econômica são de nossa valia para este estudo, ela que compreendemos ser os "[...] estudos do desenvolvimento econômico e social" (SZMRECSÁNYI, 2008, p.32), e, portanto, deve concentrar suas atenções "[...] fundamentalmente nas mudanças e/ou na permanência das estruturas econômicas através do tempo, e, portanto, no estudo de suas causas, de seus mecanismos e de suas consequências" (SZMRECSÁNYI, 2008, p.33), é neste sentido, que pretendemos para o período abordado compreender as permanências ou mudanças na atividade cafeeira no município de Ribeirão Preto. Compreendemos também que a temporalidade proposta por este estudo é característica do tempo conjuntural, tal, como propõem Braudel: "[...] há assim, ao lado do relato [...], um recitativo da conjuntura que põem em questão o passado por longas fatias: dez, vinte ou cinquenta anos" (BRAUDEL, 2013, p.44). De tal modo, buscaremos compreender as relações entre os fluxos e influxos econômicos mundiais e a economia regional constituída no município.

\section{Economia brasileira e desenvolvimento da cafeicultura}

No que se refere ao século XIX no Brasil, uma série de eventos marcantes tomaram conta do país neste período, não podemos esquecer que ele inicia o século e pelas duas décadas seguintes se mantém, ainda, como colônia de Portugal. Este é o primeiro laço que as novas práticas econômicas oriundas, principalmente, da Grã-Bretanha acabam por romper (FURTADO, 2007, p.70; PRADO JÚNIOR, 1989, pp.74-75). Segundo Caio Prado Júnior, com a Revolução Industrial e as novas práticas produtivas resultantes desta, tem vez um novo agente econômico, o empresário industrial, que diferente do comerciante colonial, não consegue vantagem nenhuma com o "Pacto Colonial". Esta prática apenas favorece a Metrópole e seus agentes, deixando os demais de fora dos circuitos econômicos brasileiros, de modo que: "O interesse do comércio e de seus manipuladores no Pacto é obvio, pois, o seu fim não é senão reservar para a Metrópole, e, portanto, seus comerciantes, o 


\section{artigos}

\section{A Atividade Cafeeira em Ribeirão Preto/SP (1904-1936)}

privilegio das transações comerciais em prejuízo de concorrentes estrangeiros"(PRADO JÚNIOR, 1989, pp. 74-75).

Ao cortar os laços coloniais com Portugal, o Brasil finalmente consegue condições para inserir-se na economia internacional, entretanto, por sua condição de ex-colônia e uma série de fatores que podemos apontar como sociais e materiais. Foram impostas ao Brasil uma série de condições exógenas para o seu desenvolvimento, ou seja, que não participavam da realidade nacional e não respondiam as contradições existentes no país (PRADO JÚNIOR, 1989, p. 79).

Segundo Celso Furtado, a economia brasileira do final do século XVIII até a primeira metade do século XIX estava envolta por uma crise, e apesar das tentativas de se implantar um sistema administrativo eficiente, este apenas serviu ao propósito de manter a unidade nacional frente a recente independência (FURTADO, 2007, p.164). Como Caio Prado Jr. já havia apontado, as pressões oriundas da Grã-Bretanha vinham surtindo pouco efeito de modo que poucas técnicas de produção resultantes da Revolução Industrial haviam penetrado no país. A situação fiscal tão pouco estava melhor, sem um aparelho estatal eficiente e tendo contraído uma soma expressiva de empréstimos internacionais pra finalidades improdutivas, a situação fiscal se tornou precária, a falta de crédito público reduziu o potencial produtivo do país e sua capacidade de importar e exportar fazendo com que o aumento de impostos e taxas não fosse uma opção viável. Neste cenário, as inversões indiretas se mostraram extremamente escassas já que não se oferecia um ambiente adequado para a manutenção de atividades lucrativas. desde modo, Celso Furtado aponta:

Num país sem técnica própria e no qual praticamente não se formavam capitais que pudessem ser desviados para novas atividades, a única saída que oferecia o século XIX para o desenvolvimento era o comércio internacional (FURTADO, 2007, p.165).

Neste cenário um novo produto se apresenta, o café, usufruindo de condições favoráveis tanto no cenário econômico externo como interno, o produto logo apresentou-se aos empresários que apostaram nele grande rentabilidade. 


\section{artigos}

Ulysses de Paiva Faleiros Neto

Para Celso Furtado, os empresários, que promoveram a produção cafeeira no Brasil, eram em sua maioria antigos mercadores que acumularam capitais durante o ciclo aurífero mineiro, abastecendo as regiões de mineração:

O abastecimento desse mercado passou a constituir a principal atividade econômica dos núcleos de população rural que se haviam localizado no sul da província de Minas como reflexo da expansão da mineração. [...] muitos desses homens, que haviam acumulado alguns capitais no comercio e transporte de gêneros e de café, passaram a interessar-se pela produção deste, vindo a constituir a vanguarda da expansão cafeeira. (FURTADO, 2007, pp. 170-171)

Celso Furtado nos apresenta uma perspectiva bastante interessante acerca da formação deste grupo, originaria de uma classe mercante, sua formação se deu em uma frente ampla, ou seja, atuavam em diversas atividades. Segundo o autor: "[...] aquisição de terras, recrutamento de mãode-obra, organização e direção de produção, transporte interno, comercialização nos portos, contatos oficiais, interferência na política financeira e econômica" (FURTADO, 2007, 171-172).

O que se pode apontar, é que esse novo grupo que se formava no Brasil, tinha poder suficiente e condições para atuar dentro do campo político e econômico, primeiro porque se constituíram no período de independência do Brasil, e, portanto, foram capazes de se afirmar junto ao novo governo, ainda mais representando tão importante parcela da economia brasileira logo no primeiro decênio da independência, a expansão cafeeira também foi responsável, finalmente, por reintroduzir o Brasil no comércio internacional, logo, gerando capitais suficientes para promover novas expansões que direcionaram a produção cafeeira rumo ao Oeste Paulista.

\section{Ocupação do território e início da produção cafeeira em Ribeirão Preto/SP}

Ernesta Zamboni, em relação a área de Ribeirão Preto, afirma: “[...], até o final do século XVIII, era pouco conhecida e constituía zona de passagem às minas de ouro. Em suas proximidades passava o "Caminho de Goiases", que ligava São Paulo ao triângulo mineiro e ao território goiano 


\section{artigos}

\section{A Atividade Cafeeira em Ribeirão Preto/SP (1904-1936)}

[...]" (ZAMBONI, 1978, p.14). Não obstante, segunda ela apenas com a decadência do ciclo aurífero mineiro é que um novo fluxo migratório ocorre, só que desta vez de Minas Gerais para São Paulo:

Todo o processo de ocupação e povoamento da área em estudo está inserido no movimento de fluxo e refluxo de uma população envolvida no processo de florescimento e desagregação da atividade mineradora (ZAMBONI, 1978, p. 27).

A forma de ocupação das terras na região, posterior a decadência do ciclo aurífero mineiro, foi preponderante para entendermos a formação da estrutura produtiva em torno do café em Ribeirão Preto. É difícil precisar se as terras que compunham a área eram parte de uma sesmaria ou terras devolutas (LOPES, 2011, p.20-21; ZAMBONI, 1978, p.20). Sendo uma sesmaria abandonada ou terras devolutas, os dois apresentam uma característica em comum: compunham um grande quinhão de terras. Os indivíduos que ocuparam essas terras foram amplamente estudados. Tal ocupação foi promovida por mineiros, através do regime da posse, como afirma Carlos Bacellar: "De uma maneira geral, recorreram à posse pura e simples de grandes quinhões de terra devoluta, exceto por alguns raros casos de solicitação de carta de sesmaria" (BACELLAR, 2001, p.175).

Se apossar da terra era um processo relativamente simples, que envolvia apenas o trabalho manual de demarcação e ocupação do solo, legitimar essas terras é que se mostrou um processo complicado e frustrante. O município de Ribeirão Preto, está intimamente ligada a este processo, tanto que podemos perceber que as pressões legislativas chegam aqui logo em 1852, neste período a forma mais fácil de comprovar a legitimidade da terra era doando parte dela para a Igreja Católica (LOPES, 2011, p.26). Neste ano verificamos a primeira tentativa conjunta de indivíduos. Afim de assegurar suas posses, doaram terras para a formação de um patrimônio eclesiástico (LOPES, 2011, p.26-27), quatro posseiros: Mariano Pedrosa de Almeida, José Laves da Silva, José Mateus dos Reis e João Alves da Silva Primo doaram cerca de $120 \$ 000$ réis (lê-se cento e vinte mil réis), valor mínimo em terras que a Igreja aceitava em época, entretanto devido a uma disputa judicial que existia em uma parte delas a doação não foi aceita (OLIVEIRA, 2000, p. 48). 


\section{artigos}

Ulysses de Paiva Faleiros Neto

A segunda tentativa, em 1853 contou com doações de João Alves da Silva, Inácio Bruno Costa, Mariano Pedroso de Almeida, José Borges da Costa e Severiano João da Silva, esta doação foi aceita e dela foi formado o patrimônio de São Sebastião (OLIVEIRA, 2000, p. 48).

A região, até então um grande quinhão de terras esparsamente ocupadas, passou a oferecer melhores condições para que populações até então espalhadas pela área pudessem se fixar, desde modo: "A concentração da população em torno de uma capela criou condições para a formação de um povoado e, em 1871, este foi elevado à categoria de vila, com o nome de São Sebastião do Ribeirão Preto" (ZAMBONI, 1978, p.33), não obstante, é necessário apontar que a Lei de Terras de 1850 marcou também o início de políticas que passam a beneficiar a recente classe de cafeicultores que já vinha se formando desde o início do século XIX:

Na província de São Paulo, as atenções dos grandes proprietários territoriais dirigiam-se para o café. Assim sendo, podemos interpretar a Lei de Terras de 1850 como expressando a mentalidade da classe dominante, favorecendo a grande propriedade e criando um reservatório de mão de obra para a lavoura. (ZAMBONI, 1978, p. 37)

De modo que, o processo de formação da rede fundiária em Ribeirão Preto apresenta uma tendência majoritária para a formação da grande propriedade, principalmente, a partir de 1870, quando se começa a revelar a propensão das terras na região ao cultivo de café. Favorecidos pela Lei de Terras de 1850, grandes proprietários possuíam a sua disposição uma grande massa de trabalhadores que impossibilitados de acessar terras de cultivo, viam no trabalho assalariado uma forma de garantir seu sustento. Não obstante, neste período começam a se fixar os marcos reguladores para o início das políticas de imigração em massa e a criação de colônias agrícolas, com o objetivo de expandir a fronteira agrícola, principalmente no Estado de São Paulo (MILLIET, 1941, pp.11-15).

Podemos perceber que o avanço da fronteira agrícola em direção a região de Ribeirão Preto, modificou expressivamente os preços da terra, o que dificultou ainda mais a instalação de pequenas 
e médias propriedades na região. Podemos verificar essa evolução nos valores da terra através da tabela 01:

Tabela 01 - Ribeirão Preto: Preço médio do hectare de terra (1876 - 1891)

\begin{tabular}{cc}
\hline Ano & Preço médio por hectare (em réis) \\
\hline $\mathbf{1 8 7 6}$ & $3 \$ 845$ \\
\hline $\mathbf{1 8 7 8}$ & $8 \$ 440$ \\
\hline $\mathbf{1 8 7 9 / 1 8 8 3}$ & $14 \$ 592$ \\
\hline $\mathbf{1 8 8 4}$ & $23 \$ 603$ \\
\hline $\mathbf{1 8 8 5}$ & $25 \$ 572$ \\
\hline $\mathbf{1 8 8 6 / 1 8 8 8}$ & $32 \$ 624$ \\
\hline $\mathbf{1 8 9 1}$ & $31 \$ 068$ \\
\hline
\end{tabular}

Fonte: BACELLAR, Carlos de Almeida Prado. Do gado ao café: as transformações da estrutura fundiária de Ribeirão Preto ao longo do século XIX. Estudos de História, Franca, v. 8, n. 2, p. 173-186, 2001, p.180.

A tabela 1, demonstra que conforme Ribeirão Preto foi sendo ocupada por cafeicultores, os valores do hectare das terras sofreram grandes aumentos, justamente, a partir dos anos de 1870, quando o movimento em direção a esta região se intensificou devido as propagandas feitas na capital São Paulo. Como afirma Ernesta Zamboni: "Nesse momento, penetra o cafeicultor, o homem já experimentado em outras áreas. Para aí se dirige o homem enérgico, de iniciativa, especulador, [...]. É o homem dinâmico que derruba matas e, no lugar, [...], crescem imensos cafezais" (ZAMBONI, 1978, p. 51), o resultado deste movimento é um fluxo crescente de lavradores já experimentados na cultura do café que sucessivamente vão se estabelecer na região de Ribeirão Preto.

De tal modo, a partir desta explanação podemos buscar compreender melhor como esse processo de formação da estrutura fundiária no município se refletiu na formação da estrutura produtiva do café para o período proposto. 


\section{artigos}

Ulysses de Paiva Faleiros Neto

\section{A estrutura produtiva do café em Ribeirão Preto/SP}

Analisando os documentos primários disponíveis para o período conseguimos construir séries históricas que nos auxiliam a compreender melhor este período na região de Ribeirão Preto. Os documentos que analisamos foram: Estatística Agrícola e Zootécnica de Ribeirão Preto (1904-1905) e os Registros de Impostos sobre Comércio, Indústria, Profissões e Produção de Café (S/D), ambos disponíveis no APHRP. Pretendíamos ao analisar essas fontes, averiguar como estavam distribuídos os pés de café no município, quem eram os produtores e como eles estavam distribuídos entre pequenos, médios e grandes cafeicultores.

Ambas as fontes apresentam informações significativas que nos permitiram conduzir a análise e averiguar as hipóteses. As principais informações foram o nome do proprietário, o nome da propriedade e o número de cafeeiros (pés de café). Como nossa intenção foi constituir séries histórias buscamos trabalhar com o número total de proprietários, o total de propriedades, o número de cafeeiros por propriedade, neste sentido e através do cruzamento destas informações foi possível extrair informações e análises significativas.

Dentro de uma perspectiva ampla, conseguimos compreender melhor como a atividade cafeeira no município se comportou frente aos fluxos e influxos da economia nacional e mundial, demonstrando que a atividade mesmo que em âmbito regional não se dissociava da economiamundial.

Nossa primeira análise consistiu em criar um gráfico, buscando compreender as tendências da atividade cafeeira no município para o período abordado. Este gráfico tem início em 1904-1905, e sofre com a ausência de informações até 1916, quando finalmente temos uma série para até 1936.

No gráfico 01, poderemos observar a evolução do número de produtores de café e o número total de cafeeiros declarados nestas terras em Ribeirão Preto. Posteriormente, pretendemos desmembrar estes dados, buscando efetuar análises de caráter mais pontual sobre algumas das diversas óticas de que são possíveis refletir sobre esta documentação. 


\section{artigos}

A Atividade Cafeeira em Ribeirão Preto/SP (1904-1936)

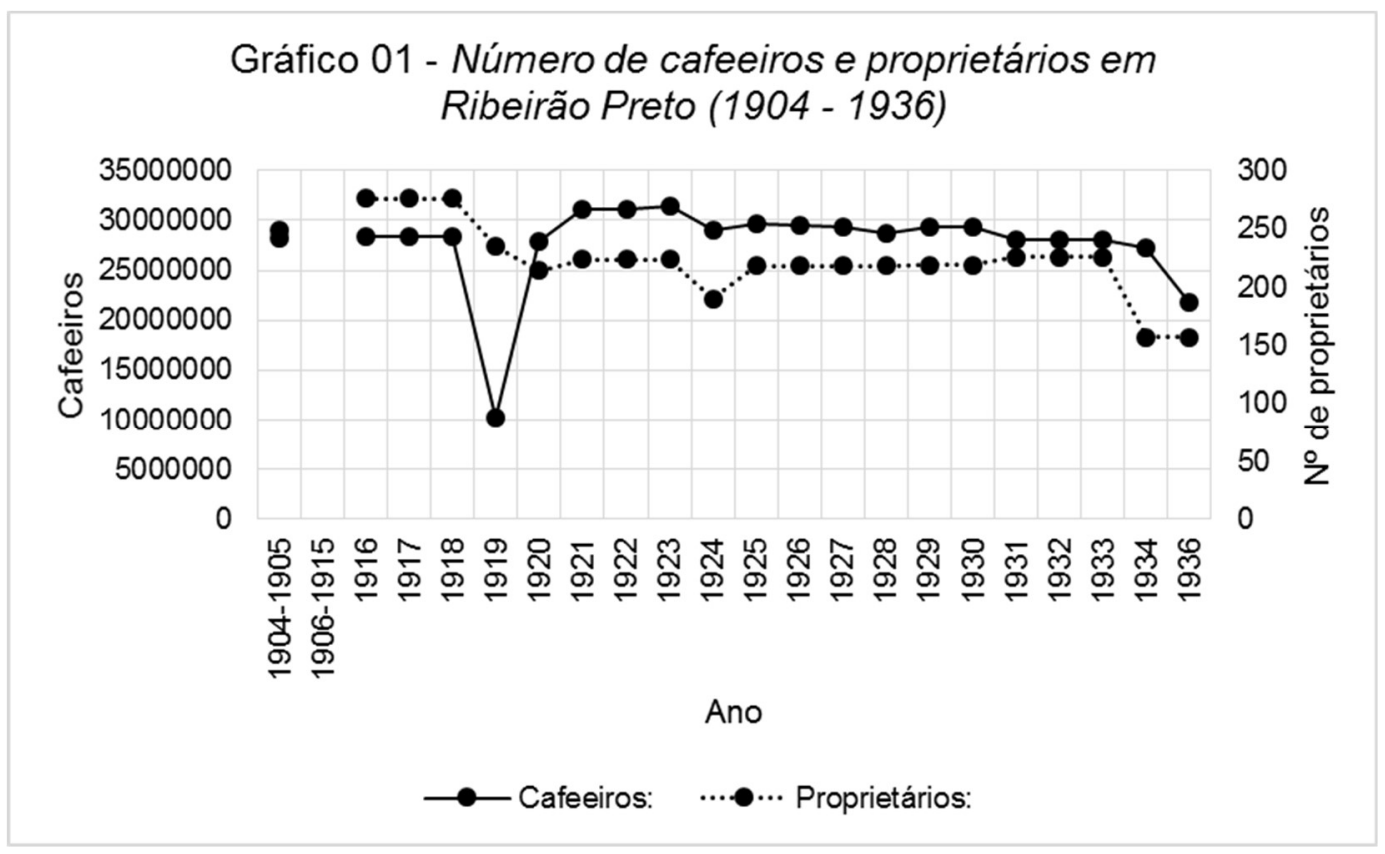

Fontes: 1904-1905: Estatística agrícola e zootechnica de Ribeirão Preto no ano agrícola de 1904-05, 1916-1936: Registros de Impostos sobre Comércio, Indústria, Profissões e Produção de Café (S/D).

Conseguimos averiguar através desta série que o número de cafeeiros e de proprietários de Ribeirão Preto, no que se refere a atividade cafeeira, sempre apresentou constância, as médias são de 27.827.395 milhões de pés de café, aonde podemos ver na legenda indicado como "cafeeiros", e uma média de 223 proprietários cadastrados durante o período abordado.

Apesar da consistência apresentada, alguns períodos nos chamam a atenção: $1^{\circ}$ ) A queda bruta no número de cafeeiros em 1919. $2^{\circ}$ ) A queda acentuada em 1924 no número de cafeeiros e produtores e sua posterior recuperação. 3º) A queda a partir de 1933.

O primeiro caso em 1919, é decorrente da geada de 1918, como as fontes se constituem em documentos do fisco, os impostos de 1918 já haviam sido pagos, de tal modo, as perdas relativas à geada só foram averiguadas em 1919. Este período foi importante na medida em que representou um momento de concentração no número de pés de café por parte dos grandes cafeicultores, podemos perceber pelo gráfico 01, que o número total de produtores que em 1916 era de 276, em 


\section{artigos}

Ulysses de Paiva Faleiros Neto

1920 não passava de 214, demonstrando que os efeitos da geada foram graves. Podemos observar na tabela 02 que o grupo mais afetado foi o dos pequenos cafeicultores.

Tabela 02 - Produtores de café por faixa de tamanho (1904 - 1920)

\begin{tabular}{cllcccc}
\hline \multicolumn{2}{r}{ Faixa de tamanho } & $\mathbf{1 9 0 4 - 0 5}$ & $\mathbf{1 9 1 6 - 1 7 - 1 8}$ & $\mathbf{1 9 1 9}$ & $\mathbf{1 9 2 0}$ \\
\hline \multirow{3}{*}{ Pequeno } & $500-1.000$ & 3 & 8 & 150 & 5 \\
\cline { 2 - 6 } & $1.001-5.000$ & 29 & 68 & 14 & 45 \\
\cline { 2 - 6 } Médio & $5.001-10.000$ & 45 & 58 & 8 & 43 \\
\cline { 2 - 6 } & $10.001-50.000$ & 73 & 68 & 18 & 54 \\
\hline \multirow{2}{*}{ Grande } & $50.001-100.000$ & 25 & 14 & 12 & 14 \\
\cline { 2 - 6 } & $100.001-500.000$ & 48 & 51 & 29 & 39 \\
\hline
\end{tabular}

Fonte: Registros de Impostos sobre Comércio, Indústria, Profissões e Produção de Café (S/D).

Após a geada de 1918, o número de pequenos produtores não se recupera para os níveis de 1916-17-18, enquanto que o número de grandes produtores aumenta sucessivamente, como é possível ver na tabela 02 e 03.

A pequena queda no número cafeeiros e produtores em 1924, nos pareceu um pouco mais difícil de explicar, segundo Antônio Delfim Netto: "A elevação dos preços em moeda nacional fora extraordinária e, em 1924, a saca de café valia, na exportação, nada menos de 205 \$853" (DELFIM NETTO, 2009, p.101). Como então explicar uma queda no número de proprietários e pés de café em um cenário de otimismo e aumento de preços? Analisando os dados com maior refino, conseguimos encontrar pistas. 
Tabela 03 - Produtores de café por faixa de tamanho (1921 - 1927)

\begin{tabular}{clccccccc}
\hline & \multicolumn{7}{c}{ Ano } \\
\hline \multirow{3}{*}{ Faixa de tamanho } & $\mathbf{1 9 2 1 - 2 2}$ & $\mathbf{1 9 2 3}$ & $\mathbf{1 9 2 4}$ & $\mathbf{1 9 2 5}$ & $\mathbf{1 9 2 6}$ & $\mathbf{1 9 2 7}$ \\
\hline \multirow{3}{*}{ Pequeno } & $500-1.000$ & 6 & 6 & 4 & 2 & 2 & 2 \\
\cline { 2 - 8 } & $1.001-5.000$ & 49 & 48 & 33 & 45 & 45 & 45 \\
\cline { 2 - 8 } & $5.001-10.000$ & 41 & 42 & 38 & 44 & 44 & 43 \\
\hline \multirow{2}{*}{ Grandio } & $10.001-50.000$ & 54 & 52 & 43 & 48 & 49 & 50 \\
\cline { 2 - 8 } & $50.001-100.000$ & 14 & 14 & 15 & 14 & 11 & 11 \\
\cline { 2 - 8 } & $100.001-500.000$ & 45 & 47 & 43 & 49 & 52 & 52 \\
\cline { 2 - 8 } & 500.001 ou Mais & 15 & 15 & 14 & 16 & 15 & 15 \\
\hline
\end{tabular}

Fonte: Registros de Impostos sobre Comércio, Indústria, Profissões e Produção de Café (S/D).

Na tabela 03 podemos perceber que em 1924, os pequenos produtores diminuem sua participação na somatória geral, em contrapartida os produtores que possuíam em suas propriedades 10.001 até 50.000 pés de café aumento, e os que possuíam 100.001 até 500.000 também aumentam. É possível supor que as condições de mercado estavam dificultando a sobrevivência destes pequenos produtores. A primeira condição que encontramos diz respeito a produção de nossos concorrentes estrangeiros: "Em 1924, nossos concorrentes já produziam 7 milhões de sacas, quando desde o início do século, essa produção não passava de 4 milhões de sacas, em média" (DELFIM NETTO, 2009, p.102). Fatores internos podem também ter levado a esta situação, em novembro de 1924, foi sancionada a Lei $n^{\circ} 4.868$, que dentre suas atribuições, proibia em até $5 \%$ as quantidades destinadas à exportação de preferência tipo 7 ou inferiores (DELFIM NETTO, 2009, p.107). Não seria de surpreender que os pequenos cafeicultores ficaram receosos ao saber que o café de menor qualidade que produziam iria sofre boicotes nas exportações. De tal modo, esses motivos parecem ter ocasionado esse susto na atividade cafeeira no município em 1924, podemos perceber que a recuperação no número total de produtores se constituiu principalmente de médios e grandes cafeeiros após 1924.

O terceiro ponto de ruptura interessante que notamos é a queda no número de produtores e cafeeiros a partir de 1933, cerca de 4 anos após o famoso "Crash de 1929". A demora na resposta da atividade a crise generalizada pelas economias mundo afora, se deveu em grande parte às 


\section{artigos}

Ulysses de Paiva Faleiros Neto

medidas protecionistas que o governo adotava desde 1906 - Convênio de Taubaté -, tais medidas atrelaram a economia cafeeira aos interesses nacionais, sendo dever da República proteger e promover seu cultivo e comércio (FURTADO, 2007, pp.253-259; DELFIM NETTO, 2009, pp.101-129). Essa cultura que por muito tempo se estabeleceu nas regiões produtoras, fez com que os produtores não se importassem com as condições do mercado ao produzirem café, de tal modo por décadas caso o mercado mundial não absorvesse a produção nacional o Estado estaria de prontidão para comprar os excedentes. Esta crença levou com que muitos produtores em 1929 não começassem a investir em outras culturas e nem se preocupassem com as consequências da crise mundial (FURTADO, 2007, pp.264-266).

Através do gráfico 01, podemos ver que a resposta à crise é muito sutil e ocorre em 1930, 31 e 32, sendo apenas em 1933 que a atividade responde de maneira generalizada no município de Ribeirão Preto. São bastante claros os sinais de esgotamento neste período na atividade cafeeira: "A produção prevista para os dez anos seguintes excedia, com sobras, a capacidade previsível de absorção dos mercados compradores. A destruição dos excedentes das colheitas se impunha, [...]" (FURTADO, 2007, pp. 266-267). A crise afetou tanto a faixa dos pequenos, de 500 até 1.000 pés como a faixa dos grandes de 500.001 ou mais pés de café. Sendo que as faixas intermediarias se mantiveram estáveis, devido principalmente à diminuição de pés de cafés nas propriedades, podemos ver isso na tabela 04.

Tabela 04 - Produtores de café por faixa de tamanho (1928 - 1936)

\begin{tabular}{clccccc}
\hline \multicolumn{2}{r}{ Faixa de tamanho } & $\mathbf{1 9 2 8}$ & $\mathbf{1 9 2 9 - 3 0}$ & $\begin{array}{c}\mathbf{1 9 3 1 - 3 2 -} \\
\mathbf{3 3}\end{array}$ & $\mathbf{1 9 3 4}$ & $\mathbf{1 9 3 6}$ \\
\hline \multirow{3}{*}{ Pequeno } & & 4 & 4 & 4 & 0 & 0 \\
\cline { 2 - 7 } & $500-1.000$ & 15 & 46 & 50 & 5 & 8 \\
\cline { 2 - 7 } & $1.001-5.000$ & 40 & 40 & 40 & 21 & 26 \\
\hline \multirow{2}{*}{ Médio } & $10.001-10.000$ & 50 & 45 & 46 & 47 & 46 \\
\cline { 2 - 7 } & $50.001-50.000$ & 12 & 14 & 16 & 20 & 16 \\
\hline \multirow{2}{*}{ Grande } & $100.001-500.000$ & 54 & 57 & 59 & 54 & 54 \\
\cline { 2 - 7 } & 500.001 ou Mais & 13 & 13 & 11 & 10 & 7 \\
\hline
\end{tabular}

Fonte: Registros de Impostos sobre Comércio, Indústria, Profissões e Produção de Café (S/D). 


\section{artigos}

A Atividade Cafeeira em Ribeirão Preto/SP (1904-1936)

Como podemos perceber, a tabela demonstra que a partir de 1933, ouve uma diminuição expressiva no número total de cafeicultores no município, doravante, além do número de proprietários diminuir o número de pés de café também seguiu essa tendência, como podemos observar no gráfico 01, a título de exemplo o maior produtor de Ribeirão Preto, a Cia. Agrícola Fazenda Dumont, em 1934 possuía 4.368.307 pés de café, apenas dois anos depois, em 1936, possuía 1.480.914 pés, demonstrando o quanto os negócios com o café se tornaram desvantajosos.

É possível notar os movimentos de concentração e desconcentração de cafeeiros através do gráfico 02, nele podemos ver momentos marcantes aonde a faixa de grandes produtores concentra os cafezais em suas mãos e posteriormente, com o início da derrocada da economia cafeeira, vão desconcentrando esses cafezais, na medida em que as faixas medianas apresentam aumento em seus cafezais.

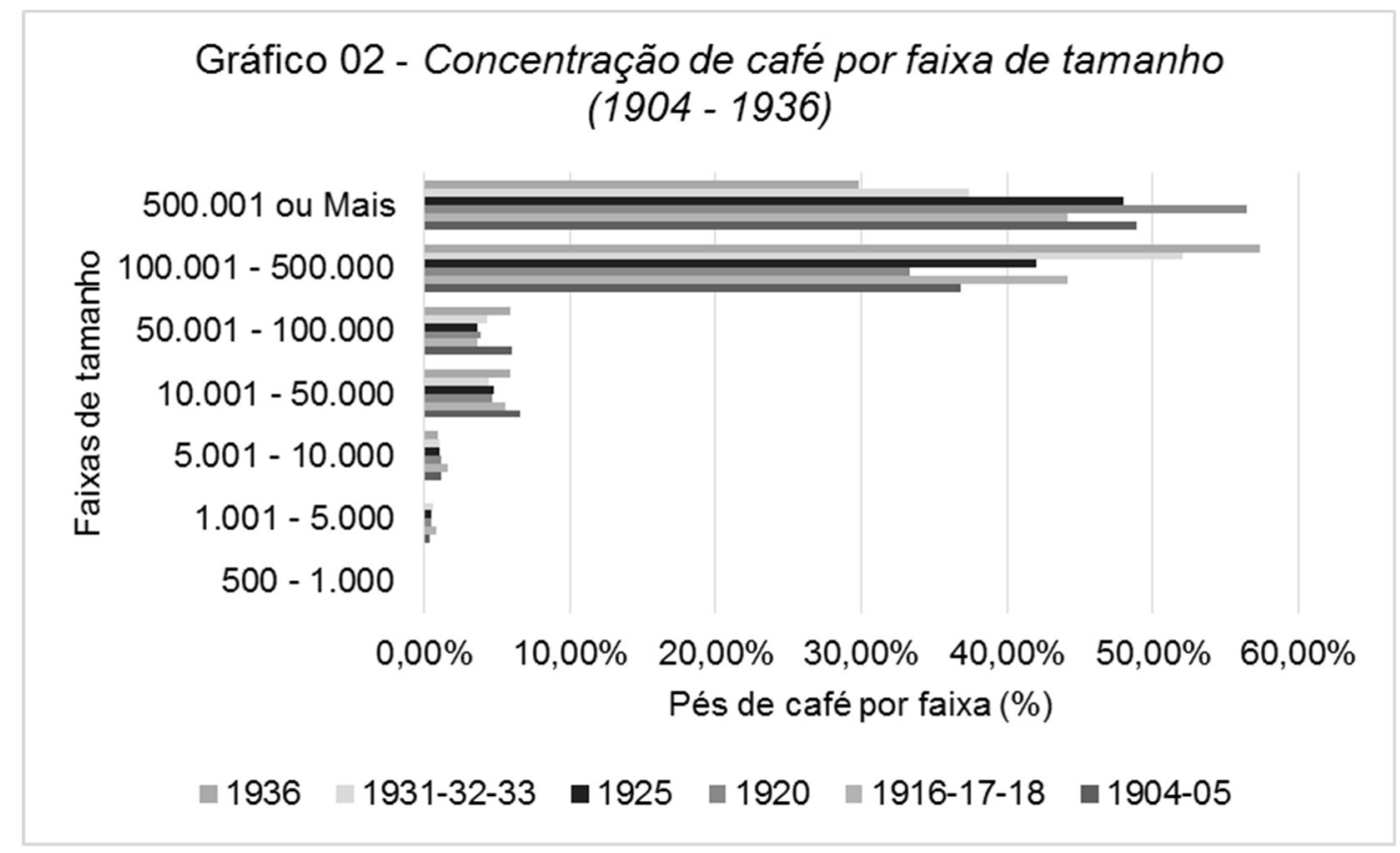

Fontes: 1904-1905: Estatística agrícola e zootechnica de Ribeirão Preto no ano agrícola de 1904-05, 1916-1936: Registros de Impostos sobre Comércio, Indústria, Profissões e Produção de Café (S/D).

Notavelmente, em 1920 os grandes cafeicultores concentravam considerável parcela dos cafezais no município, chegando a concentrar $56,41 \%$ dos cafeeiros, devido as condições ruins da 


\section{artigos}

Ulysses de Paiva Faleiros Neto

economia cafeeira, esse número vai diminuindo, sendo para 1925: 47,95\%; 1931-33: 37,37\% e 1936: 29,36\%. Seria engano achar que esses indivíduos abandonaram a atividade enquanto outros os substituíam com cafezais menores. Não houve abandono por parte dos cafeicultores, seria irracional, afinal em uma atividade como a cafeicultura, uma quantidade imensa de capital é imobilizada nas plantas. Eles apenas diminuem sucessivamente o número de cafeeiros, seja abandonando ou vendendo aos menores, isso explica o aumento da faixa de produtores entre 100.001 e 500.000 pés de café.

Entretanto, os cafeicultores, que produziam entre 10.001 e 100.000 pés, sofreram um aumento real, ou seja, novos indivíduos começaram a produzir café, talvez aproveitando a saída dos grandes, que faziam forte concorrência e impossibilitavam pequenos lucros na atividade.

\section{Considerações finais}

Ao final deste trajeto, conseguimos perceber que a economia cafeeira representou um momento de desenvolvimento para o Brasil, ainda no Império, formando um grupo que na República, conquistou o poder político, formando o que Celso Furtado, chamou de "classe de dirigentes". Este desenvolvimento a partir de 1870, principalmente, trouxe mudanças para o município de Ribeirão Preto. Usufruindo de condições climáticas e geográficas ideais para o plantio da rubiácea, logo o município se tornou um polo atrativo de novos e velhos cafeicultores, 1904-05 já possuía grandes fazendas e um considerável número de pés de café. Isso se refletiu diretamente no valor das terras aqui disponíveis para a agricultura.

As análises feitas nos documentos primários, nos possibilitaram construir séries históricas que permitiram a análise com maiores minucias do perfil do produtor local. No período analisado a atividade já estava bem estabelecida na região e essas séries nos deram condições de observar as permanências e mudanças da cafeicultura no município. Conseguimos averiguar uma predominância dos grandes produtores de café no cenário econômico de Ribeirão Preto. Estes possuíam grandes propriedades e dominavam as atividades relacionadas ao produto na região, os pés de café também mostraram uma alta concentração. É notável que em 1920, por exemplo, 14 cafeicultores 


\section{artigos}

A Atividade Cafeeira em Ribeirão Preto/SP (1904-1936)

concentrassem em suas terras, cerca de $56,41 \%$ dos pés de café do município, enquanto que no mesmo ano, os 93 produtores que possuíam até 10.000 pés de café concentravam em suas mãos $1,67 \%$ dos pés de café. Isso demonstra uma grande desigualdade nas estruturas produtivas do município, desigualdades estas, que certamente, se refletiram nos campos da políticos e sociais da cidade.

Não obstante, demonstramos que as condições econômicas (As incertezas de 1924 e o Crash de 1929) foram absorvidas pela economia local, isso significa, que o município figurava como parte da economia mundial e a atividade de alguma forma respondia ao mercado externo. Em 1924, incertezas na venda de cafés de baixa qualidade espantaram os pequenos e médios produtores, em 1925, já com a situação superada, novos produtores tomaram lugar dos que abandonaram a atividade. Em 1929, a quebra da bolsa de Nova York, levou o mundo a uma grande depressão econômica, os bens considerados commodities, como é o caso do café, perderam grande espaço no mercado mundial, e isso se refletiu claramente na atividade no município, estava claro que modelo protecionista do Estado brasileiro não poderia ajudar os produtores em 1929.

\section{Referências bibliográficas}

BACELLAR, Carlos de Almeida Prado. Do gado ao café: as transformações da estrutura fundiária de Ribeirão Preto ao longo do século XIX. Estudos de História, Franca, v. 8, n. 2, p. 173-186, 2001.

BRAUDEL, Fernand. Escritos sobre história. $3^{\circ}$ Ed. São Paulo: Perspectiva, 2013. (Debates, 131).

DELFIM NETTO, Antônio. O problema do café no Brasil. São Paulo: UNESP, 2009.

FURTADO, Celso. Formação Econômica do Brasil. 34º Ed. São Paulo: Companhia das Letras, 2007.

LOPES, Luciana Suarez. Ribeirão Preto, a dinâmica da economia cafeeira de 1870 a 1930. 2011. (Coleção Nossa História, nº 1)

MILLIET, Sérgio. Roteiro do café e outros ensaios: Contribuição para o estudo da história econômica e social do Brasil. $3^{\circ}$ Ed. São Paulo: Departamento de Cultura, 1941. 


\section{artigos}

Ulysses de Paiva Faleiros Neto

OLIVEIRA, Jorge Henrique Caldeira de. As transações imobiliárias em Ribeirão Preto de 1874 a 1899. Araraquara: Faculdade de Ciências e Letras/Universidade Estadual Paulista, Dissertação de Mestrado, 2000.

PRADO JÚNIOR. Caio. História e Desenvolvimento: A contribuição da historiografia para a teoria e prática do desenvolvimento brasileiro. $3^{\circ}$ Ed. São Paulo: Brasiliense, 1989.

SZMRECSÁNYI, Tamás. Fundamentos teóricos e metodológicos do estudo da história econômica. História econômica \& história de empresas. Vol. 11, n. 2, pp. 31-43, 2008.

ZAMBONI, Ernesta. Processo de formação e organização de rede fundiária da área de Ribeirão Preto (1874 a 1900) - uma contribuição ao estudo de estrutura agrária. 126 fls. Dissertação (Mestrado em História) - Universidade de São Paulo, Faculdade de Filosofia, Letras e Ciências Humanas, São Paulo, 1978.

\section{Fontes}

Arquivo Público e Histórico de Ribeirão Preto

Registros de Impostos sobre Comércio, Indústria, Profissões e Produção de Café (S/D). (SEM CAIXA)

SECRETARIA DA AGRICULTURA, COMÉRCIO E OBRAS PÚBLICAS. Estatística Agrícola e Zootechnica de Ribeirão Preto no Anno Agrícola de 1904 - 1905. São Paulo: Typ. Brazil/Rothschild \& Co., 1907. (SEM CAIXA) 